\title{
Diversity of gastrointestinal parasites in sympatric mammals in Moukalaba-Doudou National Park, Gabon
}

\author{
Serge-Ely Dibakou ${ }^{1}\left(\mathbb{D}\right.$, Ulrich Maloueki ${ }^{2,3}$, Barthélémy Ngoubangoye ${ }^{1}$ iD, Larson Boundenga ${ }^{1,4}\left(\mathbb{D}\right.$, Stephan Ntie $^{5}$ (D), \\ Thierry-Audrey Tsoumbou' ${ }^{1}$, Cyr Moussadji ${ }^{1}$ (D), Rina Obame Zang ${ }^{3}$, Dikenane Kombila ${ }^{3}$ and Didier Basset ${ }^{6}$
}

\begin{abstract}
1. Centre de Primatologie, Centre Interdisciplinaire de Recherches Médicales de Franceville (CIRMF), BP 769 Franceville, Gabon; 2. Department of Biology, Faculty of Sciences, Kinshasa University, PO Box 190, Kinshasa XI; 3. Protectrice des Grands Singes de la Moukalaba (PROGRAM), PO Box 861, Libreville, Tchibanga, Gabon; 4. Groupe Evolution et Transmission Inter-espèces de Parasites (GETIP) du Département de Parasitologie, Centre Interdisciplinaire de Recherches Médicales de Franceville, BP 769 Franceville, Gabon; 5. Département de Biologie, Laboratoire de Biologie Moléculaire et Cellulaire, Université des Sciences et Techniques de Masuku, BP 941, Franceville, Gabon; 6. Parasitology Laboratory, CHU Montpellier, Montpellier, France.

Corresponding author: Serge-Ely Dibakou, e-mail: sergeely@live.fr

Co-authors: UM: maloueki.ulrich@gmail.com, BN: genistha@hotmail.com, LB: boundenga@gmail.com, SN: stephanntie@yahoo.fr, TT: thierrytsoumbou@outlook.fr, CM: cyrth02@gmail.com, ROZ: zangobamerina@yahoo.fr, DK: dikenane@gmail.com, DB: didier.basset@dbmail.com

Received: 19-04-2021, Accepted: 12-11-2021, Published online: 25-12-2021
\end{abstract}

doi: www.doi.org/10.14202/vetworld.2021.3149-3155 How to cite this article: Dibakou S, Maloueki U, Ngoubangoye B, Boundenga L, Ntie S, Tsoumbou T, Moussadji C, Zang RO, Kombila D, Basset D (2021) Diversity of gastrointestinal parasites in sympatric mammals in Moukalaba-Doudou National Park, Gabon, Veterinary World, 14(12): 3149-3155.

\begin{abstract}
Background and Aim: Gastrointestinal parasites identified in the wild can negatively affect host fitness, lower performance, and growth. On the other side, sympatric mammals that share habitat and resources may also cross-transmit parasites, which are often zoonotic and can contribute to morbidity and mortality. This study aimed to characterize the diversity of gastrointestinal parasites circulating in mammalian hosts in Moukalaba-Doudou National Park.

Materials and Methods: We screened a total of 25 fecal samples collected from nine wild mammalian species, namely, western gorilla (Gorilla gorilla gorilla), chimpanzee (Pan troglodytes), putty-nosed monkey (Cercopithecus nictitans), African forest elephant (Loxodonta cyclotis), African buffalo (Syncerus caffer), blue duiker (Philantomba monticola), bay duiker (Cephalophus dorsalis), and red river hog (Potamochoerus porcus) as well as people working as trackers (Homo sapiens) using direct microscopic observations following a sedimentation technique to concentrate the fecal material.
\end{abstract}

Results: Of the total 25 fecal samples screened, 15 (60\%) were positive for parasitic gastrointestinal infection. Based on the morphology of parasite eggs and cysts, we identified a rich diversity of nematodes, protozoans, trematodes, and cestodes, including unidentified strongyles (73\%), Oesophagostomum spp. (53\%), Ancylostoma spp. (27\%), Trichuris spp. (13\%), Ascaris spp. (13\%), Mammomonogamus spp. (13\%), Strongyloides spp. (47\%), Balantidium coli (20\%), Entamoeba coli (20\%), Endolimax nana (6\%), Fasciola hepatica (6\%), Paramphistomum spp. (13\%), and Taenia spp. (6\%).

Conclusion: All parasites were found at least once in one of the hosts, and most were potentially zoonotic and responsible for several diseases of public health concern. Because of the small sample size, our findings should not be considered conclusive. Nevertheless, they highlight the diversity of gastrointestinal parasites in this area.

Keywords: conservation, coprology, gastrointestinal parasites, Moukalaba-Doudou National Park, wildlife mammals.

\section{Introduction}

Gastrointestinal parasites play an important role in mammalian health and survival because they impact host fitness. Thus, they are a major concern in the conservation of threatened species $[1,2]$. Intestinal parasites are among the most common infections worldwide, and they lead to morbidity and mortality as well as indirect ecologic pressure that influence community structure, trophic interactions, genetic variability, food web characteristics, and population decline [3-5]. The most common gastrointestinal parasites infecting

Copyright: Dibakou, et al. Open Access. This article is distributed under the terms of the Creative Commons Attribution 4.0 International License (http://creativecommons.org/licenses/ by/4.0/), which permits unrestricted use, distribution, and reproduction in any medium, provided you give appropriate credit to the original author(s) and the source, provide a link to the Creative Commons license, and indicate if changes were made. The Creative Commons Public Domain Dedication waiver (http:// creativecommons.org/publicdomain/zero/1.0/) applies to the data made available in this article, unless otherwise stated. mammalian species are protozoans, nematodes, and trematodes, which are widespread in most environments $[1,6]$.

The occurrence and prevalence of gastrointestinal parasites in mammals vary according to the geographic location, season, and habitat type [7]. For instance, tropical regions with dense equatorial forests, moist conditions, and high humidity appear to favor a diverse range of parasite eggs [8,9]. In addition, a variety of infectious diseases originating from mammalian hosts, including bats, rodents, and non-human primates, are important threats to human health. Moreover, the close phylogenetic proximity between non-human primates and humans and the expansion of human activities (e.g., mining, bushmeat hunting, farming, and logging) into the areas previously uninhabited by people $[10,11]$ increases the probability of the transmission of zoonotic pathogens to humans and vice versa. Thus, documenting the nature of the 
pathogens circulating in wild populations has become a priority. For example, Ebola hemorrhagic fever and anthrax outbreaks have decimated populations of African great apes $[12,13]$ and led to a decline in several other taxa, such as amphibians, African carnivores, and African monkeys [14,15].

This study is a preliminary attempt to characterize the gastrointestinal parasites circulating in mammalian hosts in Moukalaba-Doudou National Park (MDNP), Southwest Gabon. This park is classified as a Category II protected area by the International Union for Conservation of Nature and was listed as a World Heritage site by the United Nations Educational, Scientific, and Cultural Organization in 2005 because of its exceptionally rich fauna and flora populations. Due to its species diversity and endemism, the presence of rare and endangered species, and a high density of western gorillas and the resultant ecotourism activity based on their habituation [16], MDNP is of great interest. However, despite the high level of species richness, little is known about the gastrointestinal parasites that infect mammals inhabiting the park. Although limited data are available for wild lowland gorillas [17-19], there is a clear need for research to assess the distribution and prevalence of gastrointestinal parasites in wild animals.

In this context, this study aimed to characterize the diversity of gastrointestinal parasites circulating in mammalian hosts in Moukalaba-Doudou National Park.

\section{Materials and Methods}

Ethical approval

The study was approved by the National Ethics Committee of Gabon and with the authorization of the Gabonese Ministries of Water and Forestry, Higher Education, Scientific Research and Innovation (N॰AR0031/09/MENESRESI/CENAREST/CG/CST/ CSAR).

\section{Study period and site}

We conducted this field study on September 23-24, 2019, during the monitoring of a habituated gorilla group in MDNP (Figure-1). Trained local trackers monitor this gorilla group as part of the Protectrice des Grands Singes de la Moukalaba (PROGRAM) project. This park covers $5028 \mathrm{~km}^{2}$ and consists of a mix of vegetation types, including primary forest, secondary forest, riverine forest, montane forest, and savanna [16]. Our research camp, Douguetsi (about $23.01 \mathrm{~km}^{2}$ ), is located on the northeast side of the park, at the following coordinates $02^{\circ} 22^{\prime} 11.42$ " S, $10^{\circ} 33^{\prime} 44.53$ " E, approximately from $6 \mathrm{~km}$ from Doussala village along the right side of the Moukalaba River.

\section{Sampling}

We opportunistically collected fresh fecal samples as soon as possible after defecation during routine reconnaissance patrols of the habituated gorilla group [20]. We collected a total of 25 fecal samples from nine species of wild mammals. Five species were non-human primates, including western gorilla
(Gorilla gorilla gorilla), chimpanzee (Pan troglodytes), putty-nosed monkey (Cercopithecus nictitans), and African forest elephant (Loxodonta cyclotis), and four species were ungulates, including African buffalo (Syncerus caffer), blue duiker (Philantomba monticola), bay duiker (Cephalophus dorsalis), and red river hog (Potamochoerus porcus) (Table-1). We also collected stool samples from people working as trackers (Homo sapiens) after explaining the purpose of our study and obtaining their signed consent. Fresh samples were stored at ambient temperature at the PROGRAM base camp for a maximum of 3 days before being taken to the pathology laboratory at the Centre Interdisciplinaire de Recherches Médicales de Franceville (CIRMF) for parasitological examination.

\section{Parasite identification}

Direct microscopic observations were performed after using a sedimentation technique to concentrate the fecal material. Briefly, approximately $1 \mathrm{~g}$ of fecal material was weighed out and added to $6 \mathrm{~mL}$ of Bailenger solution (15 g sodium acetate, $3.60 \mathrm{~mL}$ acetic acid, and $1000 \mathrm{ml}$ distilled water) in a Parasep filter fecal concentrator tube (manufactured by VWR International, France). Then, the solution was mixed using a tongue depressor and vortexed. Next, the homogenized solution was centrifuged at $1225 \mathrm{x} \mathrm{g}$ (1500 rpm) for $3 \mathrm{~min}$, and $4 \mathrm{~mL}$ of the supernatant was gently decanted. Finally, $20 \mu \mathrm{L}$ of the sediment was pipetted onto a glass slide and covered with a coverslip $(22 \times 32 \mathrm{~mm})$. The slide was examined at $10 \times, 40 \times$, and $100 \times$ for parasite identification [21]. Helminth eggs, protozoan trophozoites, and cystic stages were identified according to their morphologic characteristics (e.g., shape, size, color, and internal and external structure of eggs, cysts, or trophozoites) [22,23].

\section{Results}

Of the total 25 fecal samples screened, 15 (60\%) were positive for parasitic gastrointestinal infection

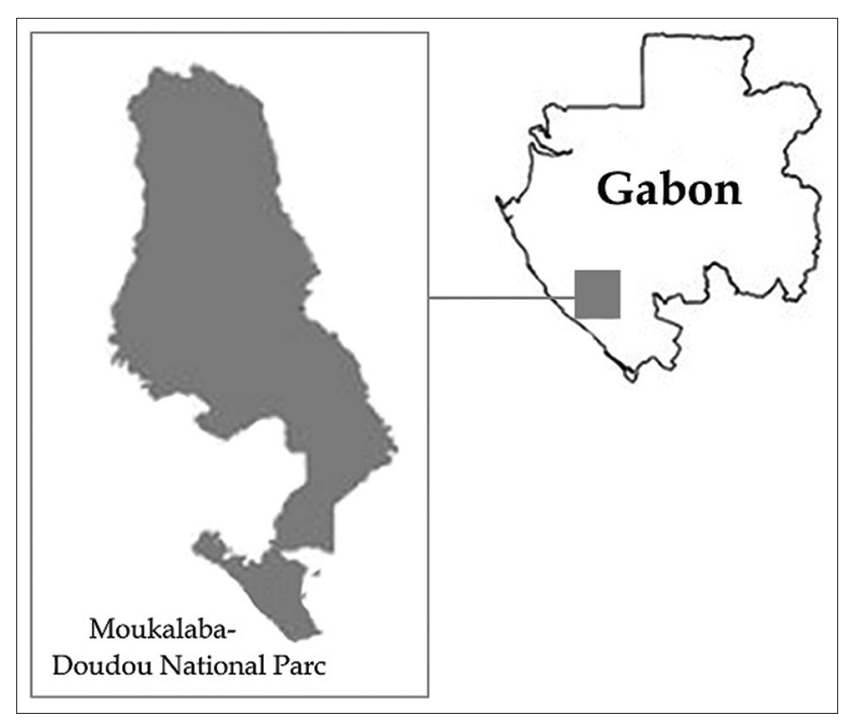

Figure-1: Moukalaba-Doudou National Park in Gabon [20]. 


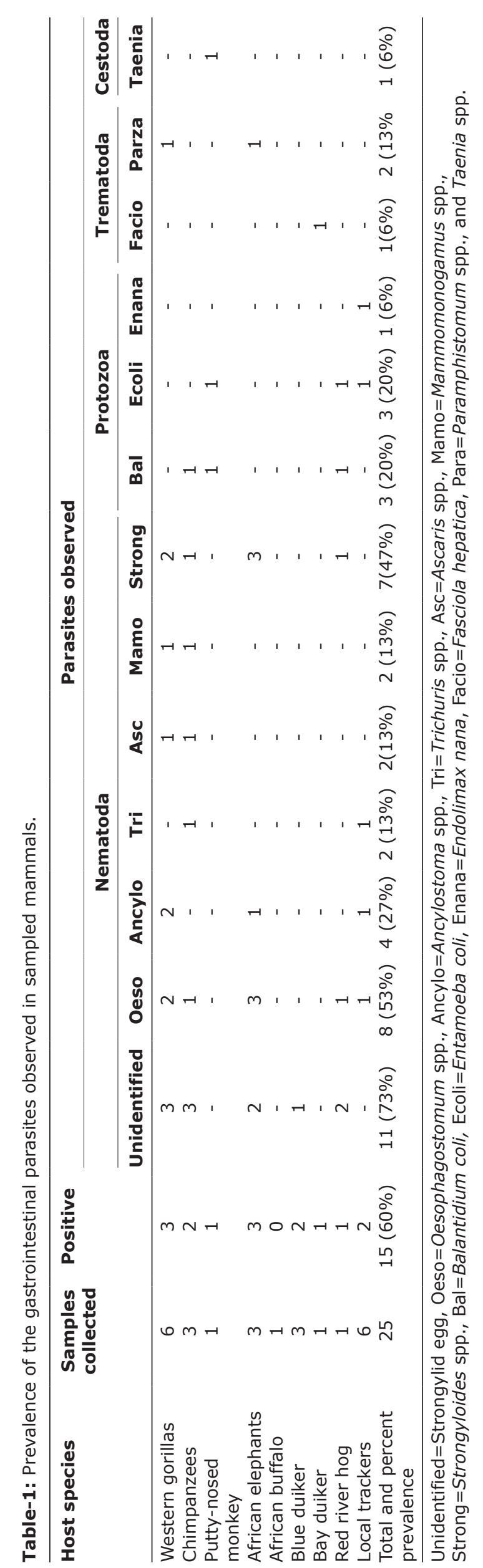

(Table-1). Based on morphologic characteristics of the parasite eggs and cysts, we identified a rich diversity of nematodes, protozoans, trematodes, and cestodes, including unidentified strongyles (73\%), Oesophagostomum spp. (53\%), Ancylostoma spp. (27\%), Trichuris spp. (13\%), Ascaris spp. (13\%), Mammomonogamus spp. (13\%), Strongyloides spp. (47\%), Balantidium coli (20\%), Entamoeba coli (20\%), Endolimax nana (6\%), Fasciola hepatica (6\%), Paramphistomum spp. (13\%), and Taenia spp. $(6 \%)$. Overall, nematodes (six taxa) were more common than protozoa (three taxa), trematodes (two taxa), and cestodes (one taxon).

We identified six nematodes (Trichuris spp., Ancylostoma spp., Oesophagostomum spp., Strongyloides spp., Mammomonogamus spp., and Ascaris spp.), two protozoans (B. coli and E. coli), one trematode (Paramphistomum spp.), and one cestode taxon (Taenia spp.) in non-human primates (Figures-2-4). In African forest elephants, we identified three nematodes (Strongyloides egg, Oesophagostomum spp., and Strongyloides spp.) and one trematode (Paramphistomum spp.) (Figure-5). In ungulates, we identified two nematodes (Strongyloides spp. and Oesophagostomum spp.), two protozoans (B. coli and E. coli), and one trematode (F. hepatica) (Figure-6). In people working as trackers, we identified three nematodes (Trichuris spp., Oesophagostomum spp., and Ancylostoma spp.) and one protozoan (E. nana) (Figure-7).

\section{Discussion}

To the best of our knowledge, this is the first study to assess gastrointestinal parasites in a wide range of mammals living in MDNP, including non-human primates (western gorilla, chimpanzee, and putty-nosed monkey), African forest elephants, ungulates (African buffalo, blue duiker, bay duiker, and red river hog), and people working as trackers. The overall prevalence of parasitic gastrointestinal infection was $60 \%$. This is slightly higher than in the previous studies performed in the same habitat $[17,19]$. The taxonomic richness of parasites was highest in western gorillas and chimpanzees, followed by elephants and people working as trackers. These differences may result from differences in sampling frequency between the hosts or from other factors that contribute to the development, survival, and dispersal of the infective stages of parasites in the environment.

\section{Parasites detected}

We detected 12 species of gastrointestinal parasites (three protozoans and nine helminths) in the host species studied, of which Oesophagostomum spp. was the most prevalent (53\%). The detection of infections caused by this parasite is crucial because of its severity and zoonotic potential. Moreover, this nodular worm can cause serious illnesses, resulting in the deaths of non-humans [24-26]. The higher 

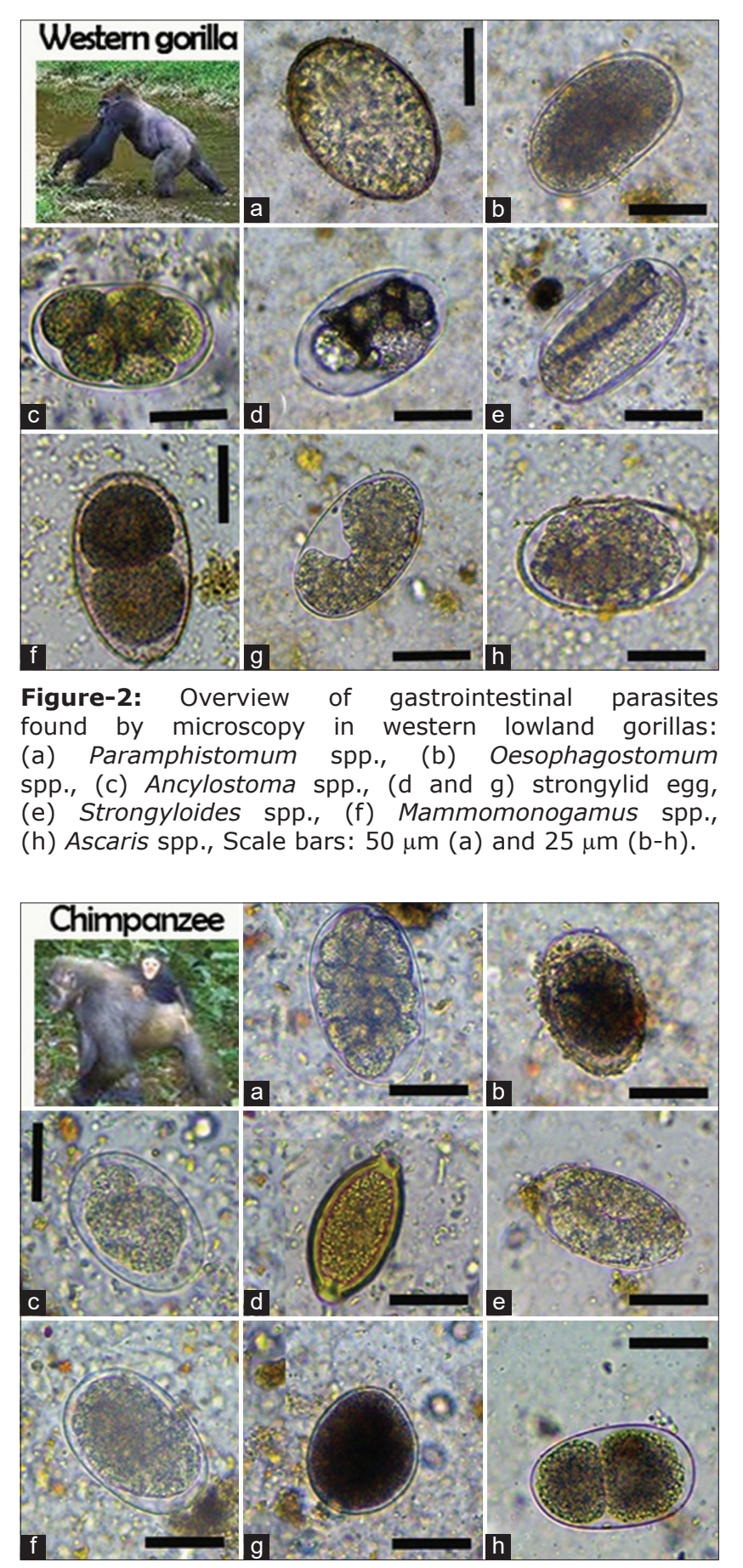

Figure-3: Overview of gastrointestinal parasites found by microscopy in chimpanzees: (a) Oesophagostomum spp., (b) Ascaris spp., (c and f) strongylid egg, (d) Trichuris spp., (e) Strongyloides spp., (g) Balantidium coli; (h) Mammomonogamus spp. Scale bars: $25 \mu \mathrm{m}$ (a-g).

prevalence of Oesophagostomum spp. compared with the other parasites that we identified may indicate the greater potential of this parasite to infect a wide range of mammalian species and suggests that it is highly infective and efficiently transmitted.

The second most prevalent intestinal nematode was Strongyloides spp., with a prevalence of $47 \%$. This zoonotically significant threadworm is of public health interest because it may lead to severe gastroenteritis, hepatitis, pneumonia, myocarditis, and death [24]. In addition, the mortality rate from such an infection and its comorbidities is $>80 \%$ [27].

The third most prevalent intestinal nematode was Ancylostoma spp. This zoonotic nematode is a blood-feeding parasite that may cause eosinophilic enteritis, and it has been associated with mild-to-severe clinical pathologies, including anemia and diarrhea, protein malnutrition, dysentery, weight loss, and death in primates $[28,29]$.

$B$. coli is a zoonotic parasite that causes severe pathology in the intestinal tract, such as diarrhea, rectal prolapse, and hemorrhagic dysentery, in both humans and animals [30]. E. coli is a protozoa that can lead to the death of the host animal in heavy infestations [31].

Other helminth species (Trichuris spp., Mammomonogamus spp., Ascaris spp., and Paramphistomum spp.) had a prevalence of 13\%, respectively. These parasites are also pathogenic. For example, Trichuris spp. was reported to significantly alter the behavior of primate hosts [32], cause intestinal disorder, and even induce death [33]. The clinical manifestations of infections of Mammomonogamus spp. include a persistent dry cough accompanied by hemoptysis and asthma, weight loss, pleuritic pain, or nausea [34]. Ascaris spp. are one of the most prevalent helminth infections in humans and animals, and infections are associated with diarrhea, malnutrition, and impaired growth and development, which can lead to death [35]. Paramphistomum spp. is a trematode that can cause serious clinical disease, especially in heavy infestations [36].

$E$. nana, Taenia spp., and $F$. hepatica all had a prevalence of $6 \%$, respectively. E. nana is a non-pathogenic ameba. Taenia spp. are cestodes associated with the most neglected tropical disease in humans worldwide [37]. F. hepatica is associated with intestinal tissue damage, hemorrhage, and death in free-ranging African elephants [36].

\section{Host species sampled}

Our results of intestinal parasite prevalence for western gorillas are similar to those of the previous studies [19]. Little is known about the prevalence of gastrointestinal parasites that infect other mammalian species in the same habitat. However, the parasitic taxa that we identified in non-human primates are all species that can infect other non-human primates and have a high potential for transmission to humans because of their simple life cycles [38,39]. Other than the absence of protozoa in gorillas and chimpanzees, the gastrointestinal nematodes identified in our study are similar to those in the previous studies of the same or closely related populations and cause asymptomatic or mild disorders $[19,38,40]$. Some of the nematodes that we identified, such as Strongyloides spp., Oesophagostomum spp., and Trichuris spp., commonly parasitize wild apes [38,41]. For instance, Oesophagostomum spp. are associated with morbidity and mortality in some primate populations [25]. 


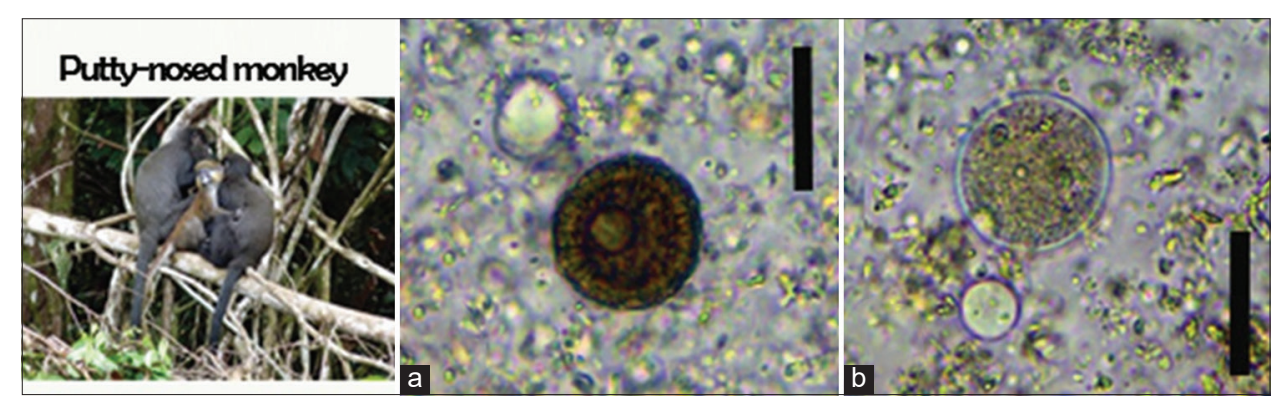

Figure-4: Overview of gastrointestinal parasites found by microscopy in putty-nosed monkeys: (a) Taenia spp., (b) Balantidium coli, Entamoeba coli. Scale bars: $20 \mu \mathrm{m}$ (a and b).

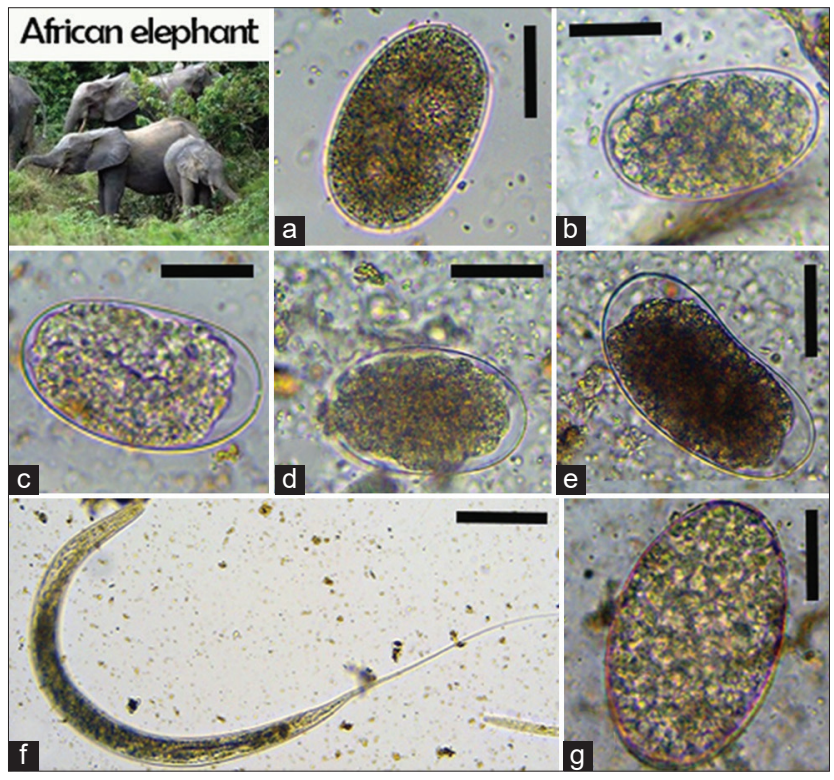

Figure-5: Overview of gastrointestinal parasites found by microscopy in elephants: (a,e) Strongylid egg, (b, d) Oesophagostomum spp., (c) Strongyloides spp., (f) Oesophagostomum larvae; (g) Paramphistomum spp. Scale bars: $25 \mu \mathrm{m}(\mathrm{a}-\mathrm{e})$ and $50 \mu \mathrm{m}(\mathrm{g})$.

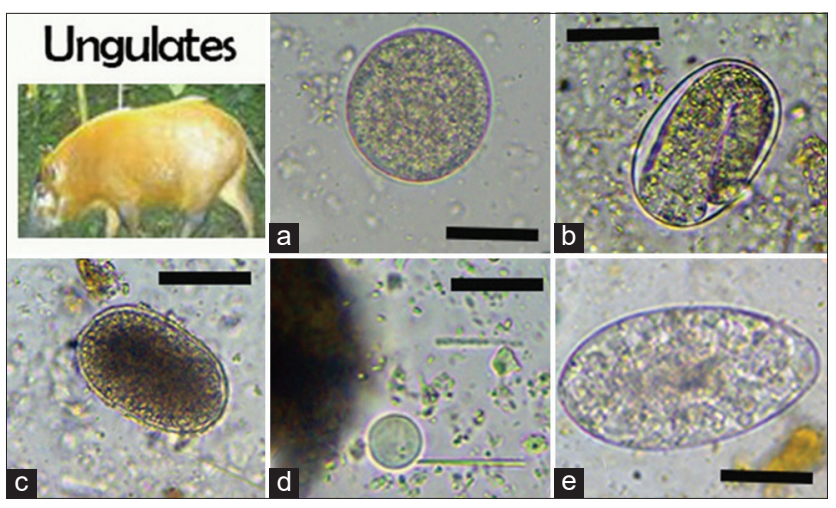

Figure-6: Overview of gastrointestinal parasites found by microscopy in ungulates: (a) Balantidium coli, (b) Strongyloides spp., (c) Oesophagostomum spp., (d) Entamoeba coli; (e) Fasciola hepatica. Scale bars: 25 $\mu \mathrm{m}(\mathrm{a}-\mathrm{c}), 10 \mu \mathrm{m}(\mathrm{d})$, and $50 \mu \mathrm{m}(\mathrm{e})$.

Our parasitological examinations of African forest elephants found one trematode genus (Paramphistomum spp.), two nematode genera (Oesophagostomum spp. and Strongyloides spp.), and unidentified nematode eggs. Elephants are most commonly parasitized by a diverse range of nematode

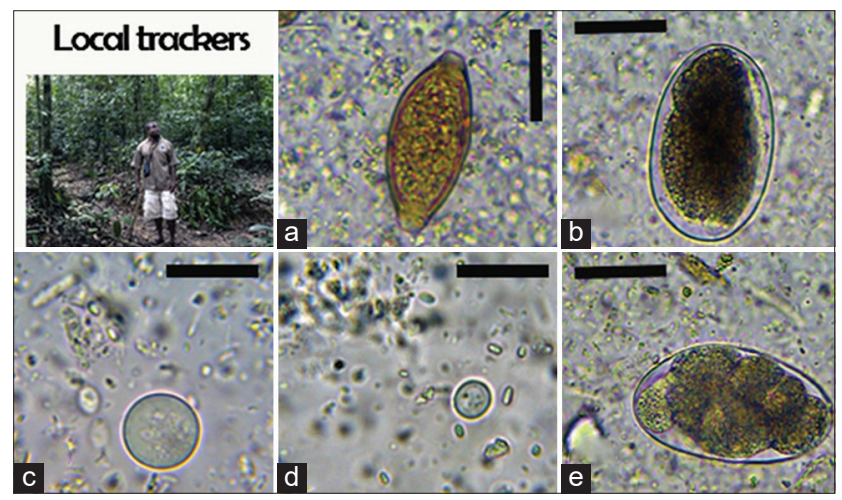

Figure-7: Overview of gastrointestinal parasites found by microscopy in local human trackers: (a) Trichuris spp.; (b) Oesophagostomum spp.; (c) Entamoeba coli; (d) Endolimax nana; (e) Ancylostoma spp. Scale bars: $25 \mu \mathrm{m}$ (a-b, e), $15 \mu \mathrm{m}$ (c), and $10 \mu \mathrm{m}$ (g-i).

(Murshidia spp., Mammomonogamus spp., and Quilonia spp.) and trematodes (Protofasciola spp., Brumptia spp.) [42]. Despite the absence of these parasites in the African forest elephants in our study, our findings correlate with several previous reports of gastrointestinal parasites in African elephants, where the prevalence of nematode infections was 2-3 times greater than trematode infections $[42,43]$. Moreover, the absence of these nematodes and trematodes may be due to several mechanisms that depend on environmental conditions [42] or be attributed to our small sample size.

In ungulates, we identified two nematode genera that have been frequently reported (Strongyloides spp. and Oesophagostomum spp.) and two protozoa genera that have been documented less often in this group $(B$. coli and E. coli). These results correlate with studies showing that ungulates are infested with a wide variety of gastrointestinal parasites [44]. Nevertheless, we did not identify gastrointestinal nematodes that typically parasitize several species of ungulates, such as Moniezia spp., Cooperia spp., and Teladorsagia spp. This lack of detection may be due to our small sample size.

The fecal analysis of local trackers working in and around MDNP revealed the presence of three nematode genera (Trichuris spp., Oesophagostomum spp., and Ancylostoma spp.) and one protozoan (E. nana). Nematodes were prevalent in all of the sampled mammal 
species. The presence of these nematodes in both non-human primates and humans suggests the occurrence of multiple cryptic species that may infect both humans and non-human primates. This supports the hypothesis that indirect contact between humans and animals sharing habitats through frequent tourist visits and assistants and researchers conducting field studies increase the possibility of infection by the same parasites $[45,46]$.

\section{Conclusion}

Our results show that mammalian species in MDNP are exposed to and infected by a diverse range of gastrointestinal parasites that may be reciprocally transmitted between species. Nevertheless, because of the low sample size (a total of 25 samples from eight host species), our results should be cautiously interpreted. In the future, we plan to perform a comprehensive longitudinal study of parasites in MDNP because of their importance to conservation and ultimately to the survival of wild mammals. Finally, molecular studies are necessary to confidently distinguish the species of gastrointestinal parasites and to test the hypothesis that cross-infection occurs in this area.

\section{Authors' Contributions}

SED, UM, TT, and BN: Conceived and designed the study as well as collected the samples. SED, CM, and LB: Carried out the parasitological analysis. SED and DB: Carried out the morphological identification analysis. SED and UM: Supervised, reviewed, and edited the manuscript. SN, BN, ROZ, and DK: Prepared funding acquisition and project administration. All authors read and approved the final manuscript.

\section{Acknowledgments}

We are grateful to PROGRAM and Agence Nationale des Parcs Nationaux of Gabon for their technical supports and permission to conduct this research in MDNP. Our gratitude goes to the CIRMF where we carried out all analyses in the laboratory. This study was financially supported by the US Found Wildlife Service (USFWS, USA) (\#F18AS00091 to PROGRAM, Gabon) as well as Fonds Français pour 1'Environnement Mondial-Programme de Petites Initiatives (FFEM-PPI, France). We also thank Prof. Joanna Setchell for her edits and comments on the original manuscript.

\section{Competing Interests} interests.

The authors declare that they have no competing

\section{Publisher's Note}

Veterinary World remains neutral with regard to jurisdictional claims in published map and institutional affiliation.

\section{References}

1. Nunn, C. and Altizer, S. (2006) Infectious Diseases in Primates: Behavior, Ecology and Evolution, Oxford
University Press, Oxford.

2. Thompson, R.C.A., Lymbery, A.J. and Smith, A. (2010) Parasites, emerging disease and wildlife conservation. Int. J. Parasitol., 40(10): 1163-1170.

3. Akinyi, M.Y., Jansen, D., Habig, B., Gesquiere, L.R., Alberts, S.C. and Archie, E.A. (2019) Costs and drivers of helminth parasite infection in wild female baboons. J. Anim. Ecol., 88(7): 1029-1043.

4. Budischak, S., Neal, D., Jolles, A.E. and Ezenwa, V.O. (2017) Differential host responses to parasitism shape divergent fitness costs of infection. Funct. Ecol., 32(2): 324-333.

5. Poulin, R. and Morand, S. (2000) The diversity of parasites. Q. Rev. Biol., 75(3): 277-293.

6. Holt, R.D., Dobson, A.P., Begon, M., Bowers, R.G. and Schauber, E.M. (2003) Parasite establishment in host communities. Ecol. Lett., 6(9): 837-842.

7. Scala, A., Tamponi, C., Sanna, G., Predieri, G., Dessì, G., Sedda, G., Buono, F., Cappai, M.G., Veneziano, V. and Varcasia, A. (2020) Gastrointestinal strongyles egg excretion in relation to age, gender, and management of horses in Italy. Animals (Basel), 10(12): 2283.

8. Beveridge, I. (2020) Mammal parasites in arid Australia. Int. J. Parasitol. Parasites Wildl., 12(8): 265-274.

9. Getachew, M., Trawford, A., Feseha, G. and Reid, S.W.J. (2010) Gastrointestinal parasites of working donkeys of Ethiopia. Trop. Anim. Health Prod., 42(1): 27-33.

10. Gillespie, T.R., Nunn, C.L. and Leendertz, F.H. (2008) Integrative approaches to the study of primate infectious disease: Implications for biodiversity conservation and global health. Am. J. Phys. Anthropol., 137(S47): 53-69.

11. Chomel, B.B., Belotto, A. and Meslin, F.X. (2007) Wildlife, exotic pets, and emerging zoonoses. Emerg. Infect. Dis., 13(1): 6-11.

12. Lahm, S.A., Kombila, M., Swanepoel, R. and Barnes, R.F.W. (2007) Morbidity and mortality of wild animals in relation to outbreaks of Ebola haemorrhagic fever in Gabon, 19942003. Trans. R. Soc. Trop. Med. Hyg., 101(1): 64-78.

13. Leroy, E.M., Rouquet, P., Formenty, P., Souquière, S., Kilbourne, A., Froment, J.M., Bermejo, M., Smit, S., Karesh, W., Swanepoel, R., Zaki, S.R. and Rollin, P.E. (2004) Multiple ebola virus transmission events and rapid decline of Central African Wildlife. Science, 303(5656): 387-390.

14. Jones, K.E., Patel, N.G., Levy, M.A., Storeygard, A., Balk, D., Gittleman, J.L. and Daszak, P. (2008) Global trends in emerging infectious diseases. Nature, 451(7181): 990-993.

15. Pounds, J.A., Bustamante, M.R., Coloma, L.A., Consuegra, J.A., Fogden, M.P.L., Foster, P.N., La Marca, E., Masters, K.L., Merino-Viteri, A., Puschendorf, R., Ron, S.R., Sánchez-Azofeifa, G.A., Still, C.J. and Young, B.E. (2006) Widespread amphibian extinctions from epidemic disease driven by global warming. Nature, 439(7073): 161-167.

16. Ando, C., Iwata, Y. and Yamagiwa, J. (2008) Progress of habituation of western lowland gorillas and their reaction to observers in Moukalaba-Doudou National Park, Gabon. Afr. Stud. Monogr., 39: 55-69.

17. Hasegawa, H., Shigyo, M., Yanai, Y., McLennan, M.R., Fujita, S., Makouloutou, P., Tsuchida, S., Ando, C., Sato, H. and Huffman, M.A. (2017) Molecular features of hookworm larvae (Necator spp.) raised by coproculture from Ugandan chimpanzees and Gabonese gorillas and humans. Parasitol. Int., 66(2): 12-15.

18. Langhout, M., van Zijll, Reed, P. and Fox, M. (2010) Validation of multiple diagnostic techniques to detect Cryptosporidium sp. and Giardia sp. in free-ranging western lowland gorillas (gorilla gorilla gorilla) and observations on the prevalence of these protozoan infections in two populations in Gabon. J. Zoo. Wildl. Med., 41(2): 210-217.

19. Makouloutou, P., Nguema, P.M., Fujita, S., Takenoshita, Y., Hasegawa, H., Yanagida, T. and Sato, H. (2014) Prevalence and genetic diversity of Oesophagostomum stephanostomum in wild lowland gorillas at Moukalaba-Doudou 
national park, Gabon. Helminthologia, 51(2): 83-93.

20. Maloueki, U., Ismaila, N., Zang, R.O. and Kombila, D. (2020) Conservation efforts and monitoring gorillas at Douguesti site, Gabon. Gorilla J., 60: 24-26.

21. Poirotte, C., Basset, D., Willaume, E., Makaba, F., Kappeler, P.M. and Charpentier, M.J.E. (2016) Environmental and individual determinants of parasite richness across seasons in a free-ranging population of Mandrills (Mandrillus sphinx). Am. J. Phys. Anthropol., 159(3): 442-456.

22. Deluol, A., Lebras, P. and Ricq, G. (1999) Colour atlas of parasitology. Vol. 2, Flagellates-Ciliates-CoccidiaMicrosporidia-Blastocystis Hominis-Trichomonas Vaginalis, St Maur: Varia.

23. Deluol, A., Hellegouarc'h, A., Lebras, P. and Ricq, G. (1998) Colour Atlas of Parasitology. Vol. 1. Varia, Amoebae, St Maur.

24. Chapman, C.A., Gillespie, T.R. and Speirs, M.L. (2005) Parasite prevalence and richness in sympatric colobines: Effects of host density. Am. J. Primatol., 67(2): 259-266.

25. Terio, K.A., Lonsdorf, E.V., Kinsel, M.J., Raphael, J., Lipende, I., Collins, A., Li, Y., Hahn, B.H., Travis, D.A. and Gillespie, T.R. (2018) Oesophagostomiasis in non-human primates of Gombe national park, Tanzania: Oesophagostomiasis in Gombe primates. Am. J. Primatol., 80(1): e22572.

26. Ngoubangoye, B., Boundenga, L., Dibakou, S.E., Tsoumbou, T.A., Kinga, C.M., Prugnolle, F., Fouchet, D. and Pontier, D. (2021) Surgical treatment of Oesophagostomum spp. nodular infection in a chimpanzee at the CIRMF primatology Center, Gabon. Case Rep. Vet. Med., 2021: 6617416.

27. Hauber, H.P., Galle, J., Chiodini, P.L., Rupp, J., Birke, R., Vollmer, E., Zabel, P. and Lange, C. (2005) Fatal outcome of a hyperinfection syndrome despite successful eradication of Strongyloides with subcutaneous ivermectin. Infection, 33(5-6): 383-386.

28. Bartsch, S.M., Hotez, P.J., Asti, L., Zapf, K.M., Bottazzi, M.E., Diemert, D.J. and Lee, B.Y. (2016) The global economic and health burden of human hookworm infection. PLoS Negl. Trop. Dis., 10(9): e0004922.

29. Seguel, M. and Gottdenker, N. (2017) The diversity and impact of hookworm infections in wildlife. Int. J. Parasitol. Parasites Wildl., 6(3): 177-194.

30. Gillespie, T.R. (2010) Book review: Primate parasite ecology: The dynamics and study of host-parasite relationships. Am. J. Hum. Biol., 22(3): 425-426.

31. Stanley, S.L. (2003) Amoebiasis. Lancet, 361(9362): 1025-1034.

32. Wren, B., Ray, I.S., Remis, M., Gillespie, T.R. and Camp, J. (2021) Social contact behaviors are associated with infection status for Trichuris sp. in wild vervet monkeys (Chlorocebus pygerythrus). PLoS One, 16(4): e0240872.

33. Wren, B., Gillespie, T.R., Camp, J.W. and Remis, M.J. (2015) Helminths of vervet monkeys, Chlorocebus aethiops, from Loskop dam nature reserve, South Africa. Comp. Parasitol., 82(1): 101-108.

34. Gutierrez, Y. (2011) Other Tissue nematode infections. In: Tropical Infectious Diseases: Principles, Pathogens and Practice. Elsevier, Amsterdam, Netherlands. p778787. Available from: https://www.linkinghub.elsevier. com/retrieve/pii/B9780702039355001129. Retrieved on 13-08-2019.

35. Bethony, J., Brooker, S., Albonico, M., Geiger, S.M., Loukas, A., Diemert, D. and Hotez, P.J. (2006) Soiltransmitted helminth infections: Ascariasis, trichuriasis, and hookworm. Lancet, 367(9521): 1521-1532.

36. Obanda, V., Iwaki, T., Mutinda, N.M. and Gakuya, F. (2011) Gastrointestinal parasites and associated pathological lesions in starving free-ranging African elephants. J. Wildl. Res., 41(2): 167-172.

37. Budke, C.M. Jr., A.C.W. and Garcia, H.H. (2009) Zoonotic larval cestode infections: Neglected tropical diseases? PLoS Negl. Trop. Dis., 3(2): e319.

38. Kouassi, R.Y.W., McGraw, S.W., Yao, P.K., AbouBacar, A., Brunet, J., Pesson, B., Bonfoh, B., N'goran, E.K. and Candolfi, E. (2015) Diversity and prevalence of gastrointestinal parasites in seven non-human primates of the Taï National Park, Côte d'Ivoire. Parasite, 22: 1.

39. Nunn, C.L. and Altizer, S.M. (2005) The global mammal parasite database: An online resource for infectious disease records in wild primates. Evol. Anthropol., 14(1): 1-2.

40. Huffman, M.A. and Chapman, C.A., editors. (2009) Primate Parasite Ecology: The Dynamics and Study of Host-Parasite Relationships. Cambridge University Press, Cambridge, New York, UK.

41. Ghai, R.R., Simons, N.D., Chapman, C.A., Omeja, P.A., Davies, T.J., Ting, N. and Goldberg, T.L. (2014) Hidden population structure and cross-species transmission of whipworms (Trichuris spp.) in humans and non-human primates in Uganda. PLoS Negl. Trop. Dis., 8(10): e3256.

42. King'ori, E., Obanda, V., Chiyo, P.I., Soriguer, R.C., Morrondo, P. and Angelone, S. (2020) Patterns of helminth infection in Kenyan elephant populations. Parasit. Vectors, 13(1): 145 .

43. Mbaya, A.W., Ogwiji, M. and Kumshe, H.A. (2013) Effects of host demography, season and rainfall on the prevalence and parasitic load of gastrointestinal parasites of free-living elephants (Loxodonta africana) of the Chad Basin national park, Nigeria. Pak. J. Biol. Sci., 16(20): 1152-1158.

44. Obanda, V., Maingi, N., Muchemi, G., Ng'ang'a, C.J., Angelone, S. and Archie, E.A. (2019) Infection dynamics of gastrointestinal helminths in sympatric non-human primates, livestock and wild ruminants in Kenya. PLoS One, 14(6): e0217929.

45. Clough, D. (2010) Gastrointestinal parasites of red-fronted lemurs in Kirindy Forest, Western Madagascar. J. Parasitol., 96(2): 245-251.

46. Loudon, J.E., Sauther, M.L., Fish, K.D., HunterIshikawa, M. and Ibrahim, Y.J. (2006) One reserve, three primates: Applying a holistic approach to understand the interconnections among ring-tailed lemurs (Lemur catta), Verreaux's sifaka (Propithecus verreauxi), and humans (Homo sapiens) at Beza Mahafaly special reserve, Madagascar. Ecol. Environ. Anthropol., 2(2): 21. 